\title{
A LIBERDADE DE EXPRESSÃO NA REPÚBLICA FEDERATIVA DO BRASIL: ASPECTOS DESTACADOS ACERCA DA RATIFICAÇÃO DA CONVENÇÃO AMERICANA SOBRE DIREITOS HUMANOS PELO BRASIL
}

\author{
FREEDOM OF EXPRESSION IN THE FEDERATIVE REPUBLIC \\ OF BRAZIL: HIGHLIGHTED ASPECTS REGARDING BRAZIL'S \\ RATIFICATION OF THE AMERICAN CONVENTION ON HUMAN \\ RIGHTS
}

\begin{abstract}
Thalyta dos Santos Mestranda em Direito na Universidade Federal de Santa Catarina. Pós-graduada em Direito Público Constitucional e Administrativo pela UNIVALI. Professora do Curso de Direito da Faculdade Cenecista de Joinville - FCJ.
\end{abstract}

Submissão em 07.10.2016

Aprovação em 15.10.2016

DOI: http://dx.doi.org/10.21671/rdufms.v2i1.2276

Resumo: Dentre as liberdades constitucionalmente garantidas encontra-se a liberdade de expressão, considerada uma das mais importantes para o pleno exercício da vida em comunidade pelo ser humano. Nesse sentido, o presente artigo tem como principal objeto de estudo o direito à liberdade de expressão no Brasil, em especial os méritos e eventuais limitações trazidos pela ratificação da Convenção Americana sobre Direitos Humanos. A abordagem do problema foi efetivada pelo método indutivo e a técnica utilizada foi a bibliográfica, buscando-se analisar como se desenvolveu a proteção dessa liberdade no Brasil após a ratificação da Convenção Americana sobre Direitos Humanos.

Palavras-chave: Direito fundamental; liberdade de expressão; proteção constitucional; Convenção Americana sobre Direitos Humanos.

Abstract: Freedom of expression is among the freedoms guaranteed by the Constitution. It is considered one of the most important freedoms for the full exercise of life in community by the human being. In this sense, the main object of study in this article is the right of freedom of expression in Brazil, in particular the merits and possible limitations brought by the ratification of the American 
Convention on Human Rights. The approach to the problem was carried out by the inductive method and the technique used was bibliographic, seeking to analyze how the protection of this freedom was developed in Brazil after the ratification of the American Convention on Human Rights.

Keywords: Fundamental right; freedom of expression; constitutional protection; American Convention on Human Rights.

SuMÁRIO: 1. Introdução. 2. Liberdade de expressão: uma visão ampla. 2.1 Do direito à liberdade ao direito à liberdade de expressão. 2.2 Liberdade de expressão: conceitos e características. 3. Liberdade de expressão no regime constitucional brasileiro. 3.1 A Constituição Política do Império do Brasil de 1824. 3.2 A Constituição da República dos Estados Unidos do Brasil de 1891. 3.3 A Constituição da República dos Estados Unidos do Brasil de 1934. 3.4 A Constituição da República dos Estados Unidos do Brasil de 1937. 3.5 A Constituição dos Estados Unidos do Brasil de 1946. 3.6 A Constituição da República Federativa do Brasil de 1967. 3.7 A Constituição da República dos Estados Unidos do Brasil de 1988. 4. Avanços recentes: o Brasil no Sistema Interamericano de Proteção aos Direitos Humanos e a atuação da Relatoria para a Liberdade de Expressão. Conclusão. Referências.

\section{INTRODUÇÃo}

As liberdades garantidas aos indivíduos na atualidade encontram-se na categoria de direitos fundamentais, ou seja, aqueles que são atribuídos a todos e que se encontram positivados no direito constitucional dos Estados.

Dentre a gama de liberdades existentes encontra-se a liberdade de expressão, que se traduz em característica essencial da vida em sociedade, já que o ser humano necessita interagir e trocar ideias e opiniões com seus pares. A referida liberdade pode se manifestar por inúmeros modos e meios: disseminação de ideias, pensamentos, opiniões, convicções religiosas e políticas, por meio da fala, escrita ou pelos meios de comunicação em massa como televisão, rádio, jornais e internet.

Nesse contexto emerge o problema: como a proteção da liberdade de expressão se desenvolveu no Estado brasileiro e quais eventuais melhoras ocorreram após a ratificação da Convenção Americana de Direitos Humanos pelo Brasil?

Assim, o objetivo do presente estudo é a análise do direito à liberdade de expressão, a construção histórica de sua proteção e suas características no Brasil, bem como a constatação dos avanços ocorridos após a Constituição de 1988 e a ratificação da Convenção Americana de Direitos Humanos pelo Brasil.

Na efetivação da presente pesquisa, a abordagem do problema foi efetivada pelo método indutivo, tendo como ponto de partida a construção histórica da liberdade de expressão no constitucionalismo brasileiro para, posteriormente, analisar os progres- 
sos com a ratificação da Convenção Americana de Direitos Humanos. A técnica utilizada foi a pesquisa bibliográfica, procedendo-se ao estudo acurado do material publicado acerca do tema: livros, revistas, jornais, artigos, informes, relatórios, documentos oficiais, e leis. A busca bibliográfica buscará compreender melhor o tema e o problema de pesquisa que está sendo investigado, no intuito de coletar subsídios suficientes para a reflexão acerca da proteção da liberdade de expressão no Estado brasileiro.

\section{LIBERDADE DE EXPRESSÃO: UMA VISÃO AMPLA}

\subsection{Do DiREITo À LiBERDADE Ao DiREITo À LiBERDADE DE EXPRESSÃo}

A liberdade, em sua acepção jurídica, é compreendida como a faculdade do ser humano de agir e pensar de acordo com sua própria determinação, baseando-se apenas em seu juízo pessoal de valor.

A liberdade é parte da constituição do ser humano, decorrendo esta do fato do homem ser um animal racional que possui inteligência e vontade própria. (MARTINS FILHO, 2004, p.36). 0 rol das liberdades encontra-se na categoria dos direitos fundamentais, que são "aquellos derechos subjetivos que las normas de un determinado ordenamiento jurídico atribuyen universalmente a todos" (FERRAJOLI, 2001, p.291).

Assim, os direitos fundamentais são os direitos subjetivos básicos que todos os cidadãos possuem e que se encontram constitucionalmente garantidos na Constituição dos Estados.

Acerca do tema, Célia Rosenthal Zisman (2003, p.30) afirma que "através da proteção constitucional da liberdade, e da sua elevação a direito fundamental, (...) pretende-se reservar à pessoa uma área de atuação imune à intervenção do Estado e de outros indivíduos." Assim, as liberdades encontram-se em um setor da existência humana que não pode ser atingido por nenhuma proibição ou comando (KELSEN, 1998, p.48).

A liberdade plena não existiria se não houvesse a plena separação dos poderes, se no mesmo homem ou mesmo grupo de indivíduos estivessem concentrados todos os poderes do Estado (MONTESQUIEU, 2002, p.166). Nesse cerne, afirma Hans Kelsen (1998, p.48) que a liberdade somente será juridicamente garantida se a ordem jurídica proibir intrusões na mesma.

Assim sendo, a liberdade de expressão traduz-se em uma das dimensões do direito à liberdade e sua proteção consta não somente nas constituições de diversos países, mas também em diversos tratados de direitos humanos.

Conforme assevera Rui Barbosa (1978, p.100), “de todas as liberdades, a do pensamento é a maior e mais alta. Dela decorrem todas as demais. Sem ela todas 
as demais deixam mutiladas a personalidade humana, asfixiada a sociedade, entregue à corrupção o governo do Estado".

A história da liberdade de expressão remonta à Grécia antiga, com a luta pela sua proteção. Era reconhecido aos cidadãos de Atenas de forma igualitária o direito de utilizarem-se da palavra nas assembleias públicas (FARIAS, 2004, p.57). À época, o traço preponderante da democracia grega não foi a isonomia entre os cidadãos mas sim a isegoria, ou seja, o direito de todos se manifestarem publicamente nas reuniões (COMPARAT0, 1999, p.308).

Sabe-se, entretanto, que a consolidação da liberdade de expressão como direito fundamental é relativamente recente, conforme opinou Pontes de Miranda (1963, p.428):

Se consultarmos a história, sabemos quanto é recente a liberdade de pensamento. Bastaria isso para mostrar quanto ainda somos primitivos. Mesmo porque essa liberdade ainda não se adquiriu em toda a sua amplitude; nem a vemos assegurada e garantida na maioria dos povos. Muito há de caminho por se percorrer, e muita luta por travar-se, para se conservar o que se conseguiu e se obter o que se deve ser obtido.

Já na Idade Moderna, serão as revoluções americana e francesa que configurarão a liberdade de expressão como é conhecida hoje (FARIAS, 2004, p.59). No continente americano, o Virginia Bill of Rights de 1776, que posteriormente serviu de base para a Constituição Americana, já proclamava a importância da liberdade de expressão. ${ }^{25}$

Em território francês, os ideais da revolução nasceram influenciados pelo Iluminismo e pela independência americana e dois importantes documentos na história da liberdade de expressão surgiram: a Declaração dos Direitos do Homem e do Cidadão de 1789 e a consequente Constituição Francesa de 1791. A Declaração trouxe em seu artigo 11 que "A livre comunicação das ideias e das opiniões é um dos mais preciosos direitos do homem. Todo cidadão pode, portanto, falar, escrever, imprimir livremente, respondendo, todavia, pelos abusos desta liberdade nos termos previstos na lei". Ato contínuo, a Constituição Francesa garantiu em seu capítulo sobre direitos fundamentais a "liberdade a todo homem de falar, escrever, imprimir e publicar suas opiniões sem ter seus escritos submetidos a quaisquer censura ou inspeção antes de sua publicação, e exercer o culto que lhe agrada".

No século XX, com a criação da Organização das Nações Unidas após o fim da Segunda Guerra Mundial, a Assembleia Geral da referida organização, já em

${ }^{25}$ Têm-se no texto original do Virginia Bill of Rights: "12. That the freedom of the press is one of the great bulwarks of liberty, and can never be restrained but by despotick governments." Disponível em: <http://www.constitution.org/bor/vir_bor.htm>. Acesso em 05 abr. 2013.

Revista DIREITO UFMS | Campo Grande, MS | v. 2 | n. 1 | p. 101 - 119 | jul./dez. 2016 
seu primeiro período de sessões, emitiu a Resolução 59, intitulada "Calling of an International Conference on Freedom of Information", estabelecendo que "a liberdade de informação é um direito humano fundamental e pedra angular de todas as liberdades para as quais as Nações Unidas são consagradas".

Os demais documentos que nasceram do movimento pós-guerra de garantia dos direitos humanos visando coibir as atrocidades presenciadas na Segunda Guerra Mundial também abarcaram a liberdade de expressão: a Declaração Americana dos Direitos e Deveres do Homem ${ }^{26}$, a Declaração Universal dos Direitos Humanos ${ }^{27}$, o Pacto Internacional dos Direitos Civis e Políticos ${ }^{28}$ e a Convenção Americana sobre Direitos Humanos ${ }^{29}$.

\footnotetext{
${ }^{26}$ Conforme artigo IV da Declaração: Toda pessoa tem direito à liberdade de investigação, de opinião e de expressão e difusão do pensamento, por qualquer meio. In: Declaração Americana dos Direitos e Deveres do Homem. Abr. 1948. Disponível em: <http://www.cidh.oas.org/basicos/portugues/b.Declaracao_Americana.htm>. Acesso em 06 abr. 2013.

${ }^{27}$ Conforme artigo XIX da Declaração Universal: Toda pessoa tem direito à liberdade de opinião e expressão; este direito inclui a liberdade de, sem interferência, ter opiniões e de procurar, receber e transmitir informações e idéias por quaisquer meios e independentemente de fronteiras. In: Declaração Universal dos Direitos Humanos. 10 dez. 1948. Disponível em: <http://portal.mj.gov.br/ sedh/ct/legis_intern/ddh_bib_inter_universal.htm>. Acesso em 21 abr. 2013.
}

${ }^{28}$ Assevera o art. 19 do Pacto Internacional de Direitos Civis e Políticos: 1. Ninguém poderá ser molestado por suas opiniões. 2. Toda pessoa terá direito à liberdade de expressão; esse direito incluirá a liberdade de procurar, receber e difundir informações e ideias de qualquer natureza, independentemente de considerações de fronteiras, verbalmente ou por escrito, em forma impressa ou artística, ou qualquer outro meio de sua escolha. 3. O exercício do direito previsto no $\S 2$ o do presente artigo implicará deveres e responsabilidades especiais. Consequentemente, poderá estar sujeito a certas restrições, que devem, entretanto, ser expressamente previstas em lei e que se façam necessárias para: a) assegurar o respeito dos direitos e da reputação das demais pessoas; b) proteger a segurança nacional, a ordem, a saúde ou a moral pública. In: Pacto Internacional sobre Direitos Civis e Políticos. 16 dez. 1996. Disponível em: <http://portal.mj.gov.br/sedh /ct/ legis_intern/pacto_dir_politicos.htm>. Acesso em: 06 abr. 2013.

${ }^{29} \mathrm{O}$ art. 13 da Convenção Americana, que trata da liberdade de pensamento e de expressão assevera: 1. Toda pessoa tem o direito à liberdade de pensamento e de expressão. Esse direito inclui a liberdade de procurar, receber e difundir informações e idéias de qualquer natureza, sem considerações de fronteiras, verbalmente ou por escrito, ou em forma impressa ou artística, ou por qualquer meio de sua escolha. 2. 0 exercício do direito previsto no inciso precedente não pode estar sujeito à censura prévia, mas a responsabilidades ulteriores, que devem ser expressamente previstas em lei e que se façam necessárias para assegurar: a) o respeito dos direitos e da reputação das demais pessoas; b) a proteção da segurança nacional, da ordem pública, ou da saúde ou da moral públicas. 3. Não se pode restringir o direito de expressão por vias e meios indiretos, tais como o abuso de controles oficiais ou particulares de papel de imprensa, de frequências radioelétricas ou de equipamentos e aparelhos usados na difusão de informação, nem por quaisquer outros meios destinados a obstar a comunicação e a circulação de ideias e opiniões.4. A lei pode submeter os espetáculos públicos a censura prévia, com o objetivo exclusivo de regular o acesso a eles, para proteção moral da infância e da adolescência, sem prejuízo do disposto no inciso 2. 5. A lei deve proibir toda propaganda a favor da guerra, bem como toda apologia ao ódio nacional, racial ou religioso que constitua incitamento à discriminação, à hostilidade, ao crime ou à violência. In: Convenção Americana sobre Direitos Humanos. 22 nov. 1969. Disponível em: < http://www.cidh.oas.org/Basicos/Portugues/c. Convencao_Americana.htm>. Acesso em 06 abr. 2013. 


\subsection{LibERdADE DE EXPRESSÃo: ConCEITO E CARACTERÍSTICAS}

É cediço que se expressar é característica intrínseca ao ser humano, sendo parte de seu desenvolvimento social e mental comunicar-se com o outro, trocar ideias e informações, participando, assim, ativamente da vida em sociedade.

Assevera Célia Rosenthal Zisman (2003, p.35) que, "sem o direito de expressar-se livremente, o indivíduo não pode contestar as regras a ele impostas, não pode se opor às normas sociais, muitas vezes abusivas, restando dessa forma oprimido".

O homem que vive em sociedade necessita não só do direito de poder ter opiniões, ele deve poder convencer outros indivíduos de suas ideias, bem como precisa da certeza de que não será punido por suas crenças ou opiniões (BASTOS, 2001, p.44).

Para Edilsom Farias (2004, p.64), a compreensão da liberdade de expressão abarca duas perspectivas: a perspectiva subjetiva, que corresponde às teorias que afirmam ser a liberdade de expressão imperativa para a salvaguarda da dignidade da pessoa humana e do desenvolvimento livre da personalidade; e a perspectiva objetiva, cujas teorias afirmam que a liberdade de expressão é intrinsecamente ligada com a proteção dos regimes democráticos.

A liberdade de expressão, que se trata tanto do direito de emitir opiniões e informações quanto do direito de recebê-las, tem sua origem na liberdade da palavra, que, consequentemente, engloba a liberdade de pensamento, visto que nada haveria de efetivo no pensamento sem a liberdade de sua emissão (CARVALHO, 1999, p.20).

Neste cerne, insta salientar que os pensamentos, opiniões e ideias - que são o núcleo da liberdade de expressão - são impróprios para aferição do critério de verdade. Já a difusão de informação, principalmente de cunho jornalístico, requer a diligencia do comunicador no sentido de divulgar informação correta. ${ }^{30}$

Assim, considera-se o termo liberdade de expressão gênero que abarca tanto a manifestação de pensamentos, opiniões, ideias, crenças e sensações como os meios que podem ser utilizados para operacionalizar tais manifestações: atividades artísticas, meios de comunicação e imprensa, expressões científicas e intelectuais, bem como o direito de acesso a tais informações -tanto individual quanto coletivamente.

Nesse sentido, destaca Samantha Ribeiro Meyer-Pflug (2009, p.66) que "a liberdade de expressão engloba a exteriorização do pensamento, ideias, opinião, convicções, bem como e sensações e sentimentos em suas mais variadas formas, quais sejam, as atividades intelectuais, artísticas, científicas e de comunicação".

\footnotetext{
${ }^{30}$ Nesse sentido tem-se, FARIAS, 2004 p. 91; MEYER-PFLUG, 2009. p. 50 e CARVALHO, Luis Gustavo Grandinetti Castanho de, 1999, p. 24-25.
}

Revista DIREITO UFMS | Campo Grande, MS | v. 2 | n. 1 | p. 101 - 119 | jul./dez. 2016 
Seguindo essa vertente de entendimento, tanto José Afonso da Silva (2006, p.241) quanto Celso Ribeiro Bastos (2001, p.47) afirmam que somente o pensamento exteriorizado é o que tem relevância para o direito. Contrariamente, André Ramos Tavares (2007, p.553) assevera que o direito à liberdade de expressão protege também a liberdade de pensar sem a efetiva exteriorização e traz como exemplo as mensagens subliminares que ocorrem na mídia e visam influenciar o subconsciente humano.

Além da proteção, sabe-se que o direito à liberdade de expressão não é absoluto, já que a exteriorização de pensamentos não pode ferir outros direitos personalíssimos tais como a honra, a dignidade e a intimidade de outros indivíduos. 0 exercício abusivo desse direito, ferindo a regra da proporcionalidade, gera ao emissor as consequências previstas em lei.

Assim, o pleno exercício de um regime democrático passa indubitavelmente pela garantia da liberdade de expressão, como bem assevera Konrad Hesse (1998, p.302-303):

Sem a liberdade de manifestação da opinião e liberdade de informação, sem a liberdade dos "meios de comunicação de massa" modernos, imprensa, rádio e filme, opinião pública não pode nascer, o desenvolvimento de iniciativas e alternativas pluralistas, assim como "formação preliminar a vontade política" não são possíveis, publicidade da vida política não pode haver, a oportunidade igual das minorias não está assegurada com eficácia e vida política em um processo livre e aberto não se pode desenvolver.

Para Santiago Sanchéz González (1992, p.31), a liberdade de expressão é sustentada em um Estado democrático por quatro premissas, a saber:

(1) Es un medio para la realización personal. 'El fin propio del hombre es la realización de sus potencias como ser humano.La supresión de las creencias, de las opiniones o de cualquier forma de expresarse es una afrenta a la dignidad del hombre, una negación de su naturaleza; (2) Sirve para incrementar el conocimiento y descubrir la verdad a través de la exposición y discusión de las ideas; (3) Es un requisito esencial para el normal desenvolvimiento del proceso democrático. Sin libertad de expresión no puede haber participación genuina de los miembros de la sociedad en la toma de decisiones políticas; (4) Por último, hace de las comunidades humanas agregados más flexibles y adaptables y por ende más estables, y faciilita el mantenimiento de un 'equilibrio precario entre las divisiones sociales saludables y el necesario consenso'.

Cumpre, também, evidenciar que o homem necessita do direito para que sua liberdade de expressão e pensamento seja plena, vale dizer, que a lei lhe assegure esse direito e regule os meios para seu exercício (BASTOS, 2001, p.44).

Revista DIREITO UFMS | Campo Grande, MS | v. 2 | n. 1 | p. 101 - 119 | jul./dez. 2016 
Destarte, é a liberdade de expressão um direito fundamental do homem que percorreu longo caminho para ter sua garantia e, possui estreita ligação com a plena caracterização de um Estado Democrático de Direito.

\section{LIBERDADE DE EXPRESSÃo NO REgime Constitucional BRASileiro}

A proteção da liberdade de expressão no constitucionalismo brasileiro passou por muitas variações decorrentes, por certo, do momento histórico e social pelo qual a nação passava quando da adoção de cada Carta Constitucional.

\subsection{A Constituição PolítiCA do IMPÉRIO do BRASIL DE 1824}

Nasceu logo após a independência do Brasil de seu colonizador: o Estado português. Ainda assim, a Constituição de 1824 foi outorgada pelo imperador português Dom Pedro I e nasceu sob a influência das Constituições Francesa de 1791 e espanhola de 1812.

No que tange à liberdade de expressão, a Carta Constitucional de 1824 assegurava a livre manifestação do pensamento por qualquer meio e sem censura. Entretanto, estipulava também que abusos cometidos no exercício do referido direito seriam responsabilizados. ${ }^{31}$ Entretanto, com a existência do Poder Moderador que se sobrepunha em relação aos outros, não havia de fato a plena liberdade de decisões e opiniões.

\subsection{A ConsTITUIÇÃo DA REPÚBLICA dos ESTADOS UNIDOS DO BRASIL DE 1891}

Com a queda da monarquia e a proclamação da República no ano de 1889 uma nova Constituição nasceu e o Poder Moderador foi extinto.

Quanto à proteção da liberdade de expressão, a Constituição Republicana não trouxe grandes mudanças e seguiu os preceitos da Carta Constitucional anterior, sendo livre a manifestação dos pensamentos e dos cultos religiosos sem censura. A única novidade trazida pelo documento foi a expressa vedação ao anonimato. ${ }^{32}$

\footnotetext{
${ }^{31}$ Conforme artigo 179, inciso IV da Constituição de 1824: todos podem comunicar os seus pensamentos, por palavras, escritos, e publicá-los pela Imprensa, sem dependência de censura; com tanto que hajam de responder pelos abusos, que cometerem no exercício deste Direito, nos casos, e pela forma, que a Lei determinar.

${ }^{32}$ Artigo 72, par. 12 da Constituição de 1891: Em qualquer assunto é livre a manifestação de pensamento pela imprensa ou pela tribuna, sem dependência de censura, respondendo cada um pelos abusos que cometer nos casos e pela forma que a lei determinar. Não é permitido o anonimato.
}

Revista DIREITO UFMS | Campo Grande, MS | v. 2 | n. 1 | p. 101 - 119 | jul./dez. 2016 


\subsection{A Constituição da REPÚBliCA dos EsTAdos Unidos do BRASIL DE 1934}

Com a Revolução de 1930, movimento que depôs o então Presidente da República Washington Luis, Getúlio Vargas foi nomeado chefe do Governo Provisório. Feita por uma Assembleia Constituinte eleita em 1933, a referida Constituição foi inspirada na Constituição de Weimar de 1919 e na Constituição Espanhola de 1931. O sufrágio feminino e o voto secreto foram suas grandes inovações.

Em seu capítulo II que tratava dos Direitos e Garantias Individuais, assim preceituou:

Art 113 - A Constituição assegura a brasileiros e a estrangeiros residentes no País a inviolabilidade dos direitos concernentes à liberdade, à subsistência, à segurança individual e à propriedade, nos termos seguintes:

9) Em qualquer assunto é livre a manifestação do pensamento, sem dependência de censura, salvo quanto a espetáculos e diversões públicas, respondendo cada um pelos abusos que cometer, nos casos e pela forma que a lei determinar. Não é permitido anonimato. É segurado o direito de resposta. A publicação de livros e periódicos independe de licença do Poder Público. Não será, porém, tolerada propaganda, de guerra ou de processos violentos, para subverter a ordem política ou social.

Constata-se do aludido dispositivo que ele praticamente mantém o mesmo perfil da Constituição anterior abarcando mais algumas proteções, tais como o direito de resposta e a não necessidade de licença para a publicação de livros e periódicos. Entretanto, nota-se a inserção de disposição contrária à plena liberdade de expressão quando o texto permite a censura de espetáculos e diversões públicas.

\subsection{A CONSTITUIÇÃo DA REPÚBLICA dOS ESTADOS UNIDOS DO BRASIL DE 1937}

Com seu mandato chegando ao fim e para manter-se no poder por prazo indeterminado Getúlio Vargas, com base na Constituição autoritária da Polônia, outorgou a Constituição de 1937 no mesmo dia, 10 de novembro de 1937, em que deu um golpe de estado para permanecer na presidência do país.

Foi uma Constituição com caráter nitidamente antidemocrático e que tolheu o amplo direito à liberdade de expressão anteriormente garantido. Conforme dispunha o artigo 122, inciso 15 da Carta de 1937, in verbis:

Art. 122 - A Constituição assegura aos brasileiros e estrangeiros residentes no País o direito à liberdade, à segurança individual e à propriedade, nos termos seguintes:

Revista DIREITO UFMS | Campo Grande, MS | v. 2 | n. 1 | p. 101 - 119 | jul./dez. 2016 
15) todo cidadão tem o direito de manifestar o seu pensamento, oralmente, ou por escrito, impresso ou por imagens, mediante as condições e nos limites prescritos em lei.

A lei pode prescrever:

a) com o fim de garantir a paz, a ordem e a segurança pública, a censura prévia da imprensa, do teatro, do cinematógrafo, da radiodifusão, facultando à autoridade competente proibir a circulação, a difusão ou a representação;

b) medidas para impedir as manifestações contrárias à moralidade pública e aos bons costumes, assim como as especialmente destinadas à proteção da infância e da juventude;

c) providências destinadas à proteção do interesse público, bem-estar do povo e segurança do Estado.

Desta feita, a Constituição outorgada em 1937 implantou na história do Brasil um dos sistemas mais rigorosos de censura prévia ao direito de expressar-se.

Neste contexto, afirmou Francisco Campos (2001, p.44) sobre a Carta Constitucional de 1937:

Ora, a Constituição é radicalmente contrária à liberdade de opinião. Ela postula, em princípio, essa liberdade, mas, logo em seguida, a condiciona e limita em tais termos que acaba por negar o que havia postulado. Ela estabelece, com efeito, a censura prévia da imprensa. Ora, o regime da censura prévia é, precisamente, o regime da suspensão da liberdade. Não se concebe regime democrático ou representativo em que não haja liberdade de opinião.

Adicionalmente ao controle já previsto na Constituição, em 1939, através do Decreto-lei no 1.949, Getúlio Vargas criou o Departamento de Impressa e Propaganda que era responsável por fiscalizar todas as atividades de imprensa e propaganda no território nacional, incluindo a imprensa em si, cinema, teatro de diversões públicas, radiofonia, programas, artistas e auxiliares teatrais.

Assim, a Era Vargas foi marcada por severo controle dos meios de expressão e comunicação, restringido o direito de expressar-se livremente no Estado brasileiro.

\subsection{A ConSTITUIÇÃo dos Estados Unidos do BRASIL DE 1946}

A Constituição de 1946 foi promulgada pela Assembleia Nacional Constituinte do mesmo ano. Trouxe novamente as liberdades anteriormente garantidas na Constituição de 1934 e que foram suprimidas na Constituição de 1937.

Assim, dispunha a Carta de 1946 acerca da liberdade de expressão: 
Art. 141 - A Constituição assegura aos brasileiros e aos estrangeiros residentes no País a inviolabilidade dos direitos concernentes à vida, à liberdade, a segurança individual e à propriedade, nos termos seguintes: $\S 5$ o - É livre a manifestação do pensamento, sem que dependa de censura, salvo quanto a espetáculos e diversões públicas, respondendo cada um, nos casos e na forma que a lei preceituar pelos abusos que cometer. Não é permitido o anonimato. É assegurado o direito de resposta. A publicação de livros e periódicos não dependerá de licença do Poder Público. Não será, porém, tolerada propaganda de guerra, de processos violentos para subverter a ordem política e social, ou de preconceitos de raça ou de classe.

§ 7ํㅡ - É inviolável a liberdade de consciência e de crença e assegurado o livre exercício dos cultos religiosos, salvo o dos que contrariem a ordem pública ou os bons costumes. As associações religiosas adquirirão personalidade jurídica na forma da lei civil.

§ 8o - Por motivo de convicção religiosa, filosófica ou política, ninguém será privado de nenhum dos seus direitos, salvo se a invocar para se eximir de obrigação, encargo ou serviço impostos pela lei aos brasileiros em geral, ou recusar os que ela estabelecer em substituição daqueles deveres, a fim de atender escusa de consciência.

Art. 173 - As ciências, as letras e as artes são livres.

O que se percebe no texto de 1946 é uma contradição, já que no artigo 173 dispunha que as artes eram livres, mas, contrariamente, dispunha no parágrafo 5 o do artigo 143 que espetáculos e diversões públicas poderiam ser censurados.

Com o Golpe de Estado de 1964 a publicação dos chamados Atos Institucionais, os militares praticamente revogaram a Constituição de 1946. Dentre eles destaca-se o Ato Institucional no 2 que extinguiu sumariamente todos os partidos políticos existentes no país e permitiu ao Chefe do Executivo cassar mandatos e suspender direitos políticos de quaisquer cidadãos. Ademais, tal suspensão dos direitos políticos proibia os atingidos de se manifestarem, sob qualquer forma, acerca de assuntos de natureza política.

\subsection{A Constituição da RePÚbliCa FEderativa do BRASIL dE 1967}

Dando seguimento aos atos do Golpe Militar intentado por membros das Forças Armadas Nacionais, a Constituição da República Federativa do Brasil de 1967 foi outorgada em janeiro do referido ano pelo Congresso Nacional. Destaca-se, que a convocação do Congresso Nacional foi feita por intermédio do Ato Institucional no 4 em 7 de dezembro de 1966, para que votassem até o dia 24 de janeiro de 1967 um projeto de constituição já elaborado pelo Ministro da Justiça Carlos Medeiros Silva.

Revista DIREITO UFMS | Campo Grande, MS | v. 2 | n. 1 | p. 101 - 119 | jul./dez. 2016 
O texto constitucional de 1967 praticamente não se modificou em relação ao texto anterior, assegurando a livre manifestação do pensamento independentemente de censura (salvo para espetáculos e diversões públicas), o direito de resposta e a publicação de livros e jornais sem necessidade de licença. Diferentemente da Constituição anterior, o que se adicionou ao final do parágrafo oitavo do artigo 150 foi que não seriam toleradas "as publicações e exteriorizações contrárias à moral e aos bons costumes”33.

Entretanto, sabe-se que na prática o regime militar censurava severamente quaisquer tipos de manifestações contrárias ao governo, apesar do disposto no texto constitucional.

Em 1968, o governo militar publicou o Ato Institucional no 5 - AI-5 que representou à época o ápice do controle ditatorial no país, concentrando plenos poderes nas mãos do governo. Através dos poderes outorgados ao Presidente da República pelo referido Ato Institucional, o Chefe do Executivo poderia decretar recesso ao Congresso Nacional, intervir nos Estados e Municípios sem quaisquer restrições, suspender direitos políticos e cassar mandatos eletivos. Ademais, o AI-5 suspendeu a garantia de habeas corpus em casos de crimes políticos e contra a segurança nacional e dispôs, ainda, que todos os atos praticados sob sua égide estavam excluídos de qualquer apreciação judicial (BRASIL, 1967).

Ato contínuo, em 1969, a Emenda Constitucional no 1 foi decretada pela Junta Militar que governava o Brasil. Tal emenda modificou quase que completamente o texto da Constituição de 1967 no sentido de adequar o texto aos Atos Institucionais até então impostos pelos militares, com o objetivo de revestir os mesmos de "legalidade". Nesse contexto, afirmou José Afonso da Silva (2006, p.86) que,

Teórica e tecnicamente, não se tratou de emenda, mas de nova constituição. A emenda só serviu como mecanismo de outorga, uma vez que verdadeiramente se promulgou texto integralmente reformado, a começar pela denominação que se lhe deu: Constituição da República Federativa do Brasil, enquanto a de 1967 se chamava apenas Constituição do Brasil.

Deste modo, foi sob os efeitos da Emenda Constitucional de 1969 e do AI-5 que as liberdades e, consequentemente, a liberdade de pensamento e expressão sofreram suas maiores represálias na história brasileira.

\footnotetext{
${ }^{33}$ Redação original: art. $150, \S 8^{\circ}$. É livre a manifestação de pensamento, de convicção política ou filosófica e a prestação de informação sem sujeição à censura, salvo quanto a espetáculos de diversões públicas, respondendo cada um, nos termos da lei, pelos abusos que cometer. É assegurado o direito de resposta. A publicação de livros, jornais e periódicos independe de licença da autoridade. Não será, porém, tolerada a propaganda de guerra, de subversão da ordem ou de preconceitos de raça ou de classe.
}

Revista DIREITO UFMS | Campo Grande, MS | v. 2 | n. 1 | p. 101 - 119 | jul./dez. 2016 


\subsection{A ConSTITUiÇão da REPúbliCa FEDERATIVA do BRASIL de 1988}

O período de opressão arbitrária da Ditadura Militar enfrentado pelo Brasil entre os anos de 1964 e 1985 terminou com o governo do General João Baptista Figueiredo, que enfrentou diversas crises nos campos internacional, econômico e político.

Lentamente, a abertura democrática aconteceu e no ano de 1985 foi eleito o primeiro presidente não militar após o início da ditadura: Tancredo Neves. Entretanto, Tancredo foi acometido de grave doença e faleceu antes de sua posse, assumindo a presidência o seu vice-presidente José Sarney. Em 1985, é aprovada a Emenda Constitucional no 26, que convoca uma Assembleia Nacional Constituinte, que seria votada nas eleições de 1986 e que iniciaria os seus trabalhos em fevereiro de 1987.

0 processo de redemocratização do país consolidou-se com a promulgação, em 5 de outubro de 1988, da atual Constituição da República Federativa do Brasil - a "Constituição Cidadã" nas palavras de Ulysses Guimarães - que trouxe a maior proteção a direitos fundamentais da história brasileira, representando um avanço em direção à plena de democracia.

A referida Constituição, considerada um marco sem precedentes para o sistema democrático brasileiro, reconhece sem qualquer tipo de distinção a todo e qualquer indivíduo o direito de formar opiniões através de seu juízo pessoal de valores e manifestar suas opiniões seja de forma escrita, falada ou pelos meios de comunicação.

No que tange à liberdade de expressão na atual Carta Constitucional brasileira, ela encontra-se elencada no rol dos direitos fundamentais e é protegida pelo instituto jurídico das cláusulas pétreas, ou seja, não pode ser abolida da Constituição. (art. 60, § 4o, IV).

Acerca do tema, destaca Samantha Ribeiro Meyer-Pflug (2009, p.65):

A liberdade de pensamento, de expressão, ideológica e de reunião passam a ter destaque, igualmente, como a vedação a toda e qualquer espécie de censura ou licença. A liberdade de imprensa é valorizada como um elemento necessário à democracia e a promoção do debate público.

Assim, no Título II da Constituição de 1988, que trata dos direitos e garantias fundamentais tem-se disposto:

Art. 5ำ Todos são iguais perante a lei, sem distinção de qualquer natureza, garantindo-se aos brasileiros e aos estrangeiros residentes no País a inviolabilidade do direito à vida, à liberdade, à igualdade, à segurança e à propriedade, nos termos seguintes:

Revista DIREITO UFMS | Campo Grande, MS | v. 2 | n. 1 | p. 101 - 119 | jul./dez. 2016 


\section{$[\cdots]$}

IV - é livre a manifestação do pensamento, sendo vedado o anonimato;

$[\cdots]$

IX - é livre a expressão da atividade intelectual, artística, científica e de comunicação, independentemente de censura ou licença;

Ademais, complementa o artigo 220 da Constituição de 1988:

Art. 220. A manifestação do pensamento, a criação, a expressão e a informação, sob qualquer forma, processo ou veículo não sofrerão qualquer restrição, observado o disposto nesta Constituição.

$\S 1$ o - Nenhuma lei conterá dispositivo que possa constituir embaraço à plena liberdade de informação jornalística em qualquer veículo de comunicação social, observado o disposto no art. 5ํ, IV, V, X, XIII e XIV.

$\S 2$ o - É vedada toda e qualquer censura de natureza política, ideológica e artística.

Desta feita, a Carta Constitucional de 1988 caracteriza-se por proteger amplamente a liberdade de expressão e comunicação, pondo fim à censura anteriormente existente.

Destaca-se, ainda, que a proteção da liberdade de expressão contida na Constituição de 1988 não se traduz em direito absoluto, já que o próprio texto constitucional explicita as restrições, quais sejam: a vedação ao anonimato, a proteção à imagem, honra e intimidade e o direito de resposta para casos de abuso no exercício desse direito.

\section{AVANÇOS RECENTES: O BRASIl Do SISTEMA INTERAMERICANO DE Proteção dos Direitos Humanos d a ATUAÇÃo da Relatoria Para A LIBERDADE DE EXPRESSÃo}

A Organização dos Estados Americanos - OEA é um organismo regional fundado em 1948 com a assinatura em Bogotá da Carta da Organização dos Estados Americanos, que entrou em vigor em dezembro de 1951. Entre os propósitos de tal organização destaca-se "conseguir uma ordem de paz e de justiça, para promover sua solidariedade, intensificar sua colaboração e defender sua soberania, sua integridade territorial e sua independência". O Brasil ratificou o referido documento em 11 de fevereiro de 1950.

Dentro do sistema interamericano, o documento de maior importância é a Convenção Americana de Direitos Humanos, também conhecida como Pacto de San Jose da Costa Rica. Destaca-se, acerca deste documento, que apenas os Es-

Revista DIREITO UFMS | Campo Grande, MS | v. 2 | n. 1 | p. 101 - 119| jul./dez. 2016 
tados membros da OEA têm a possibilidade de aderir a ele (PIOVESAN, 2010, p.256). Foi, essencialmente, a Declaração Americana de Direitos e Deveres do Homem de 1948 que trouxe a base normativa e contribuiu para o desenvolvimento do sistema interamericano de proteção dos direitos humanos (CANÇADO TRINDADE, 2003, p.33-34).

Nesse cerne, o texto da Convenção Americana foi adotado, em 22 de novembro de 1969, na Conferência Especializada Interamericana sobre Direitos Humanos e entrou em vigor em 18 de julho de 1978, após onze Estados terem depositado seus instrumentos de ratificação ou adesão34.

Já para o Brasil, a Convenção Americana entrou em vigor apenas em 25 de setembro de 1992, quando o Estado brasileiro aderiu ao texto.35

Aderindo à Convenção,

[...] o Estado-parte tem a obrigação de respeitar e assegurar o livre e pleno exercício desses direitos e liberdades, sem qualquer discriminação. Cabe ainda ao Estado-parte adotar todas as medidas legislativas e de outra natureza que sejam necessárias para conferir efetividade aos direitos e liberdades enunciados (PIOVESAN, 2006, p.89).

Assim, o sistema interamericano de proteção aos direitos humanos tem como seu principal documento a Convenção Americana, que define um sistema de monitoramento e implementação de seus direitos que é integrado pela Comissão Interamericana de Direitos Humanos e pela Corte Interamericana de Direitos Humanos.

Especificamente acerca da proteção da liberdade de pensamento e expressão, a Relatoria Especial para a Liberdade de Expressão da Comissão Interamericana de Direitos Humanos foi criada em outubro de 1997, no 97o Período de Sessões. Foi estabelecida com caráter permanente, independência funcional e estrutura própria.

No que tange ao trabalho realizado por este órgão,

[...] la Relatoría Especial ha trabajado en la promoción del derecho a la libertad de expresión a través de la asistencia técnica en el trámite de casos, medidas cautelares y realización de audiencias, entre otros. Con el mismo propósito, y en el marco de la CIDH, la Relatoría Especial ha preparado informes temáticos y regionales, ha realizado visitas oficiales y viajes de promoción, y ha participado en decenas de conferencias y seminarios que han logrado sensibilizar y capacitar a cientos de funcionarios públicos, periodistas y defensores del derecho a la libertad de expresión (BOTERO, 2013, p.1).

\footnotetext{
${ }^{34}$ Regra prevista no artigo 74.2 da CONVENÇÃO Americana sobre Direitos Humanos. 22 nov. 1969.

${ }^{35}$ Informação disponível em < http://www.oas.org/es/cidh/mandato/Basicos/convratif.asp>. Acesso em: 01 de mai. 2016.
} 
Tal Relatoria foi criada pela Comissão Interamericana de Direitos Humanos com o objetivo de incentivar a defesa da liberdade de expressão e pensamento, por considerá-la fundamental para a existência e desenvolvimento de sistemas democráticos (BOTERO, 2013, p.3).

Desta feita, tendo o Brasil ratificado a Convenção Americana de Direitos Humanos, submete-se ele ao trabalho de promoção e investigação realizado pela Corte Interamericana, pela Comissão Interamericana e pela Relatoria Especial para a Liberdade de Expressão.

No que ao tange ao trabalho realizado pela Comissão Interamericana, oito relatórios de mérito envolvendo o Brasil e possíveis violações ao artigo 13 (liberdade de pensamento e expressão) já foram emitidos, sendo que seis casos preencheram os requisitos de admissibilidade e dois não foram admitidos.36 Ademais, um informe de mérito foi emitido no ano de 201037 e nunca houve solução amistosa de um caso envolvendo o Brasil e a violação do direito à liberdade de pensamento e expressão.

Já na Corte Interamericana, um caso brasileiro foi sentenciado em que houve a declaração da violação por parte do Brasil do artigo 13 da Convenção Americana: o caso Gomes Lund e outros vs. Brasil, cuja sentença foi emitida em 24 de novembro de 201038. Referido caso diz respeito à detenção arbitrária, tortura e desaparecimento forçado de 70 pessoas, resultante de operações do exército brasileiro que visavam erradicar a Guerrilha do Araguaia durante a ditadura militar no Brasil. Especialmente quanto à violação do artigo 13, a mesma deu-se em razão do Estado ter lesionado o direito de acesso à informação dos familiares das vítimas, especialmente porque a Convenção protege o direito que tem toda pessoa de solicitar informação que esteja em poder do Estado, no caso, acerca das vítimas desaparecidas.

Por fim, quanto ao monitoramento da proteção do direito à liberdade de pensamento e expressão realizado pela Relatoria Especial para a Liberdade de Expressão, o Brasil já foi alvo de trinta e quatro comunicados de imprensa, sendo um sobre o desaparecimento de um jornalista e trinta e três sobre jornalistas assassinados.

Assim, a entrada do Brasil no Sistema Interamericano de Proteção aos Direitos Humanos veio fortalecer o arcabouço de proteção à plena liberdade de pensamento

\footnotetext{
${ }^{36}$ Conforme informaç̧ões disponíveis em: <http://www.oas.org/es/cidh/expresion/jurisprudencia/decisiones_fondo.asp >. Acesso em: 07 mai. 2016.

${ }^{37}$ Petição 12.308. Informe n ${ }^{0}$ 37/10. Manoel Leal de Oliveira vs. Brasil. Disponível em: <http://cidh. oas.org/annualrep/2010sp/BRPU12308ES.doc>. Acesso em: 07 set. 2016.

38 Sentença completa disponível em: <http://www.corteidh.or.cr/docs/casos/articulos/seriec_219_por.pdf>. Acesso em: 10 ago. 2016.
}

Revista DIREITO UFMS | Campo Grande, MS | v. 2 | n. 1 | p. 101 - 119 | jul./dez. 2016 
e expressão que nasceu com o processo de redemocratização pós-ditadura militar e a promulgação da Carta Constitucional de 1988. A atuação do Sistema Interamericano permite aos brasileiros se salvaguardarem de eventuais ingerências arbitrárias perpetradas pelo Estado brasileiro no contexto da liberdade de pensamento e expressão.

\section{CoNCLUSÃo}

Dentre as liberdades constitucionalmente garantidas ao homem na atualidade encontramos a liberdade de expressão, cujas origens remontam à Grécia antiga.

A proteção da liberdade de expressão é considerada pela Organização das Nações Unidas pedra angular de todas as outras liberdades e encontra guarida nos mais variados instrumentos internacionais, bem como nas constituições de diversas nações. Isso porque a liberdade de expressar pensamentos e opiniões tem estreita relação com a dignidade da pessoa humana, bem como com a plena existência de regimes verdadeiramente democráticos.

No constitucionalismo brasileiro, a proteção positivada da liberdade de expressão já era encontrada na Constituição do Império de 1824. Entretanto, referida liberdade sofreu grandes limitações na história, seja pela existência do Poder Moderador, pela repressão na Era Vargas com a Constituição por ele outorgada em 1937, ou pela ditadura militar iniciada em 1964 e que trouxe um dos sistemas de censura mais severos já vistos.

A redemocratização do Brasil e a consequente edição e entrada em vigor da Constituição de 1988 mudaram a história de repressões e censuras até então sofridas pelos brasileiros nos regimes militares. A “Constituição Cidadã” de 1988 representou um marco na história constitucional do Brasil, trazendo a plena proteção das liberdades e o regime democrático livre de quaisquer censuras.

Por fim, a ratificação pelo Brasil da Convenção Americana sobre Direitos Humanos representou primeiramente a intenção do Estado em garantir a proteção dos direitos humanos nela consagrados, bem como contribuiu de forma significativa para a ampla tutela e salvaguarda do direito de expressar-se livremente sem até mesmo a interferência do poder público, contribuindo, dessa forma, para a consolidação da democracia no Brasil.

\section{REFERÊNCIAS}

BARBOSA, Rui. República: teoria e prática: textos doutrinários sobre direitos humanos e políticos consagrados na Primeira Constituição Republicana. Brasília: Câmara dos Deputados, 1978.

Revista DIREITO UFMS | Campo Grande, MS | v. 2 | n. 1 | p. 101 - 119 | jul./dez. 2016 
BASTOS, Celso Ribeiro; MARTINS, Ives Gandra. Comentários à Constituição do Brasil. 2o vol. 2a Ed. São Paulo: Saraiva, 2001.

BOTERO, Catalina. Informe anual de la Comisión Interamericana de Derechos Humanos 2012: informe de la relatoría especial para la libertad de expresión. Washington: Organización de los Estados Americanos, 2013.

BRASIL. Ato Institucional no 5, de 13 de dezembro de 1967. Diário Oficial da União, Brasília, DF, 10 fev. 1968.

CAMPOS, Francisco. Entrevista ao Correio da Manhã do Rio de Janeiro em 03 de março de 1945. In: PORTO, Walter Costa. Constituições Brasileiras: 1937. 2.ed. Brasília: Senado Federal; Ministério da Ciência e Tecnologia, Centro de Estudos Estratégicos, 2001. Disponível em: <http://www2.senado.gov.br/ bdsf/item/id/137571> Acesso em: 15 abr. 2013.

CANÇADO TRINDADE, Antônio Augusto. Tratado de Direito Internacional dos Direitos Humanos. Vol.III. Porto Alegre: Sergio Antonio Fabris Editor, 2003.

CARTA da Organização dos Estados Americanos. 30 abr. 1948. Disponível em: <http:// www.oas.org/dil/port/tratados_A-41_Carta_da_Organiza\%C3\%A7\%C3\%A3o_dos_ Estados_Americanos.pdf>. Acesso em 04 set. 2016.

CARVALHO, Luis Gustavo Grandinetti Castanho de. Direito de Informação e Liberdade de Expressão. Rio de Janeiro: Renovar, 1999.

COMPARATO, Fábio Konder. É possível democratizar a televisão? In: NOVAES, Adauto (Org.) Rede imaginária: televisão e democracia. 2.ed. São Paulo: Companhia das Letras, Secretaria Municipal de Cultura, 1999.

CONVENÇÃO Americana sobre Direitos Humanos. 22 nov. 1969. Disponível em: <https://www. cidh.oas.org/basicos/portugues/c.convencao_americana.htm>. Acesso em 06 abr. 2016.

DECLARAÇÃO Americana dos Direitos e Deveres do Homem. Abr. 1948. Disponível em: < http://www.cidh.oas.org/basicos/portugues/b.Declaracao_Americana.htm>. Acesso em 06 abr. 2016.

DECLARAÇÃO dos Direitos do Homem e do Cidadão de 1789. 26 ago. 1789. Disponível em: <http://pfdc.pgr.mpf.mp.br/atuacao-e-conteudos-de-apoio/legislacao/direitos-humanos/declar_dir_homem_cidadao.pdf >. Acesso em: 06 ago. 2016.

DECLARAÇÃO Universal dos Direitos Humanos. 10 dez. 1948. Disponível em: < http:// www.ohchr.org/EN/UDHR/Documents/UDHR_Translations/por.pdf $>$. Acesso em 21 ago. 2016.

FARIAS, Edilsom. Liberdade de Expressão e Comunicação: teoria e proteção constitucional. São Paulo: Editora Revista dos Tribunais, 2004.

FERRAJOLI, Luigi. Los fundamentos de los derechos fundamentales. Madrid, Editorial Trotta, 2001.

FRANÇA. Constituição Francesa de 1791. 03 set. 1791. Texto em inglês disponível em < http://isites.harvard.edu/fs/docs/icb.topic1069529.files/French\%20Revolution\%20 Documents/Constitution\%20of\%20France\%201791.doc>. Acesso em: 06 jul. 2016.

GONZÁLEZ, Santiago Sánchez. La libertad de expresión. Madrid: Marcial Pons, 1992.

HESSE, Konrad. Elementos de direito constitucional da República Federal da Alemanha. Trad. Luis Afonso Heck. Porto Alegre: Sergio Antonio Fabris Editor, 1998. 
KELSEN, Hans. Teoria pura do direito. Trad. João Baptista Machado. $6^{\text {a }}$ Ed. São Paulo: Martins Fontes, 1998.

MARTINS FILHO, Ives Gandra da Silva. Reflexões sobre a liberdade. Direito Público. Porto Alegre, ano 1, n.4 , p. 32-47, abr./jun.2004.

MEYER-PFLUG, Samantha Ribeiro. Liberdade de expressão e discurso do ódio. São Paulo: Editora Revista dos Tribunais, 2009.

MONTESQUIEU. Do espírito das leis. Trad. Jean Melville. São Paulo: Martin Claret, 2002.

PACTO Internacional sobre Direitos Civis e Políticos. 16 dez. 1996. Disponível em: <http://www.planalto.gov.br/ccivil_03/decreto/1990-1994/d0592.htm>. Acesso em: 22 set. 2016.

PIOVESAN, Flávia. Direitos humanos e justiça internacional: um estudo comparativo dos sistemas regionais europeu, interamericano e africano. São Paulo: Saraiva, 2006.

Direitos humanos e o direito constitucional internacional. 11.ed. São Paulo:

Saraiva, 2010.

PONTES DE MIRANDA, Francisco Cavalcanti. Comentários à constituição de 1946. 4.ed. Rio de Janeiro: Borsoi, 1963. t. IV.

RESOLUÇÃO no 59 de 14 de dezembro de 1946 da Assembleia Geral das Nações Unidas. Texto completo em inglês disponível em <http://www.un.org/documents/ga/res/1/ ares1.htm>. Acesso em 12 jun. 2016.

SILVA, José Afonso da. Curso de Direito Constitucional Positivo. São Paulo: Malheiros Editores, 2006.

TAVARES, André Ramos. Curso de Direito Constitucional. 5.ed. São Paulo: Saraiva, 2007.

VIRGINIA BILL OF RIGHTS. 12 jun. 1776. Disponível em <http://www.constitution.org/ bor/vir_bor.htm>. Acesso em 05 set. 2016.

ZISMAN, Célia Rosenthal. A liberdade de expressão na Constituição Federal e suas limitações: os limites dos limites. São Paulo: Livraria Paulista, 2003. 